\title{
Non Linear Bending Analysis on Stent Materials used as Cardiovascular Implants
}

\author{
Vasantha Kumar ${ }^{1}$, C.M Ramesha ${ }^{2}$ \\ Assistant Professor, Department of Mechanical Engineering, BIT, Mangalore, Karnataka, India ${ }^{1}$ \\ Associate Professor, Department of Mechanical Engineering, MSRIT, Bangalore, Karnataka, India ${ }^{2}$
}

\begin{abstract}
Cardiovascular disease such as atherosclerosis is one of the most common diseases in modern days which may cause pain and heart attack. Stenting is non surgical method to treat the atherosclerosis. Due to its efficiency and simplicity, the use of coronary stents in interventional procedures has rapidly increased and different stents have been introduced in the market. In order to have better output of the stent implantation, it is needed to analyze the mechanical behavior of this device before manufacturing and utilizing. The aim of this work is to investigate the biomechanical behavior of stent such as non linear bending analysis at different loading conditions by using different biomaterials. One of the most effective methods to investigate the biomechanical behavior of the stent is finite element method. A commercially available finite element package ABAQUS6.10 has been used for the analysis.
\end{abstract}

Keywords: Coronary stent; Biomaterials; Finite element method.

\section{INTRODUCTION}

Coronary Artery Disease (CAD) is the most common cause of death in the world, accounting for $48 \%$ of all deaths in the world. Coronary artery disease, also known as atherosclerosis occurs when excess cholesterol attaches itself to the walls of blood vessels. Embedded cholesterol also attracts cellular waste products, calcium and fibrin. This leads to a thickening of the vessel wall by complex interaction with constituents of the artery. The resulting pasty build-up known as plaque can narrow or even block the arteries that obstruct the flow of oxygen rich blood [1]. CADs are now a days the leading cause of death in the Western countries: a recent report of American Heart Association states that, on the basis of 2006 mortality rate, nearly 2300 Americans die of CAD each day, an average of 1 death every 38 seconds. This data explains well the high incidence of such pathologies which lead to high social and economical costs; in fact, the estimated direct and indirect cost of CVD for 2010 is $\$ 503.2$ billion [2]. Several procedures are available to revascularise a blocked artery, including balloon angioplasty and stenting, bypass surgery and atherectomy. [3] Fourty years ago, coronary artery bypass surgery $(\mathrm{CABG})$ was the popular revascularization treatment used to treat obstructive coronary artery diseases. However, it was claimed that frequent coronary closures occurred and hence emergency surgical revascularization was necessary $[4,5]$.

Stenting shows some advantages compared to other possible treatments, as it does not any surgical operation and has less complication, pain and a more rapid recovery. So the use coronary stents in interventional procedures has rapidly increased from 10\% in 1994 to over $80 \%$ in current practice[6]. In order to have the better output of stent implantation, it is needed to analyze the mechanical behavior of the stent before manufacturing and utilizing. One of the most effective methods to investigate the mechanical behavior of stent is finite element method. In comparison with expensive experiments carried out in hospitals and laboratories, numerical simulations accomplished by computers have advantages in both flexibility and cost [7].

A stent is an expandable tube like device that is inserted in to a natural conduit of the human body to restore a disease induced localized stenosis. The material used for human cardiovascular stent implants are conventional materials, with heavier density, not economical and unstable. It is observed that implant materials are affecting the coronary vessel where the failure of implant is maximum due to wear, corrosion, and fatigue; the above problems are due to improper material selection. From the literature review PEEK450G polymer shows an excellent wear resistance, chemical resistance, mechanical properties, low density material, physically stable, biocompatible and also machinable[8]. Therefore in this intended investigation, low density and stable material such as PEEK450G can be selected for cardiovascular stent implant. And also comparing this material with existing stent materials such as Magnesium AZ31 and Cobalt-Chromium L605.

Hence, aims to investigate and compare the mechanical properties of three bio-inert materials used in cardiovascular stent implantation namely PEEK450G, Magnesium AZ31, and Cobalt-Chromium L605. Therefore the study reveals a best suitable biomaterial for cardiovascular stent implants, which exhibits an outstanding biocompatibility and mechanical characteristics. 


\section{MATERIALS AND METHODS}

In the present study materials used for coronary stents are PEEK 450G (Polyether-ether ketone) Magnesium AZ31 and Cobalt-Chromium L605 alloy. Primary model of stent was produced by using commercially available software. The model was constructed on the basis of images from literature [9]. The stent has an outer diameter of $1.915 \mathrm{~mm}$, length of $15 \mathrm{~mm}$ and a thickness of $0.05 \mathrm{~mm}$. Fig. 1 shows the linear array of 5 instances stent model in its unexpanded configuration.
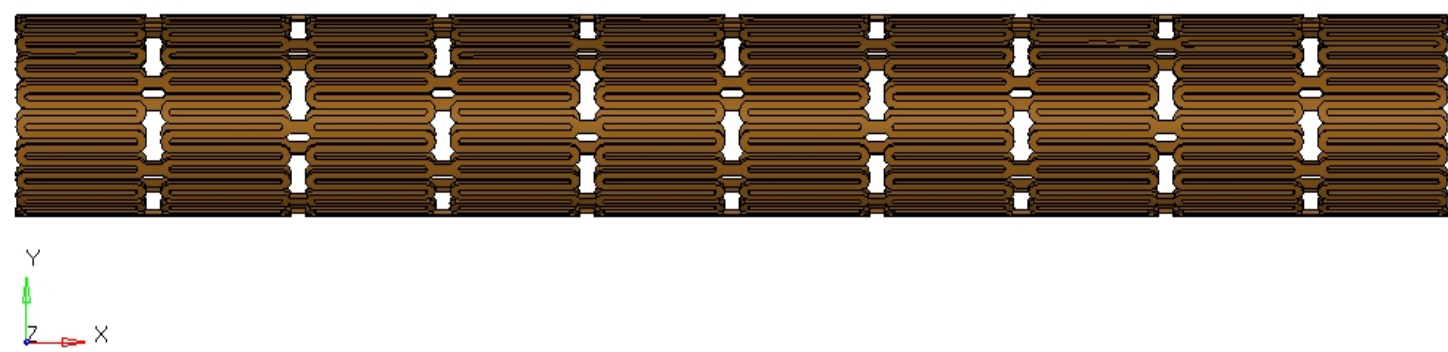

Fig 1 Linear array of 5 instances stent

\section{NON-LINEAR BENDING ANALYSIS}

In this section only stent is considered for bending analysis. The bending in stent implantation has both advantages and disadvantages. On one hand, the bending of stent causes high stress on vessel; these critical points might damage the vessel. On the other hand, the bending can help to keep stent stable against the impact of pulsed motion of blood. Thus the study of bending duration stent implantation can be very useful to modify design of stents.

\section{A. Material Properties}

The mechanical properties for Co-Cr L605 and Mg AZ31 are found in the reference [10]. Table 1 gives the mechanical properties of the two different alloys and PEEK 450G. The mechanical properties of PEEK 450G are found in VICTREX® PEEK450G medical document data is considered as per room temperature [11].

Table.1 Bio-inert material properties

\begin{tabular}{|c|c|c|c|c|}
\hline \multirow{2}{*}{ Material } & \multicolumn{3}{|c|}{ Material Properties } \\
\cline { 2 - 4 } & $\begin{array}{c}\text { Young's Modulus E } \\
\text { in }(\mathrm{MPa})\end{array}$ & $\begin{array}{c}\text { Density } \rho \\
\text { in }(\mathrm{kg} / \mathrm{mm} 3)\end{array}$ & $\begin{array}{c}\text { Poisson's } \\
\text { Ration } v\end{array}$ & $\begin{array}{c}\text { Yield Stress } \sigma \mathrm{y} \\
\text { in }(\mathrm{MPa})\end{array}$ \\
\hline PEEK 450G & 3700 & $1.30 \mathrm{E}-06$ & 0.36 & 100 \\
\hline Magnesium (MgAZ31) & 43000 & $1.70 \mathrm{E}-06$ & 0.35 & 164 \\
\hline Cobalt-Chromium (Co-Cr L605) & 243000 & $9.10 \mathrm{E}-06$ & 0.3 & 476 \\
\hline
\end{tabular}

B. Loads and Boundary conditions

Based on numerical data for biomedical stent using above three materials the deformation of the stent in terms of bending which is dealt as four different loading cases as shown in table.2, and also the one end of the stent is fixed in all DOF as shown in fig. 2

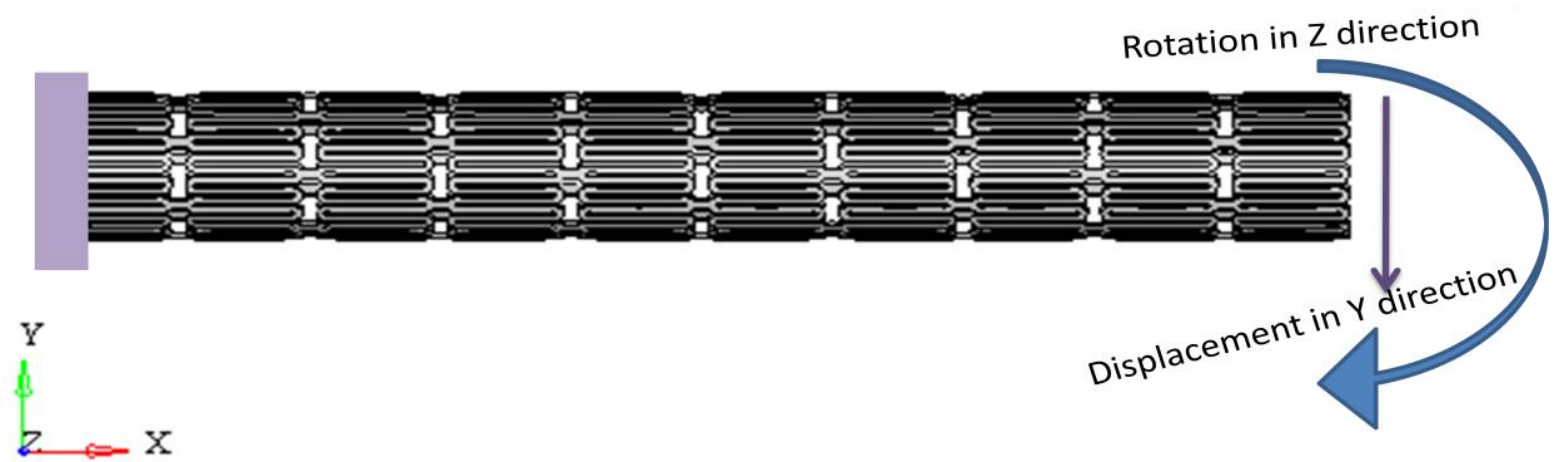

Fig.2 Stent model with loads and boundary conditions 
ISO 3297:2007 Certified

Vol. 4, Issue 5, May 2017

Table.2 Loading Cases

\begin{tabular}{|c|c|c|}
\hline Loading & Displacement-Y & Displacement-Z \\
\hline Case-1 & $1 \mathrm{~mm}$ & \\
\hline Case-2 & $2 \mathrm{~mm}$ & 0.1 radian \\
\hline Case-3 & & 0.15 radian \\
\hline Case-4 & & 0.25 adian \\
\hline
\end{tabular}

C. Finite Element Analysis

In this step FEA solver ABAQUS V6.10 is used to determine displacement and von -mises stresses for PEEK 450G, Magnesium and Cobalt-Chromium stent at different loading cases i.e. $1 \mathrm{~mm}$ displacement in $\mathrm{Y}$ direction, $2 \mathrm{~mm}$ displacement in $\mathrm{Y}$ direction with 0.1 radian rotation in $\mathrm{Z}$ direction, 0.15 radian rotation in $\mathrm{Z}$ direction and 0.25 radian rotation in $\mathrm{Z}$ direction. The analysis of PEEK 450G for the above loading cases shown in the figures 3 (a), (b), (c) and (d).

(a)
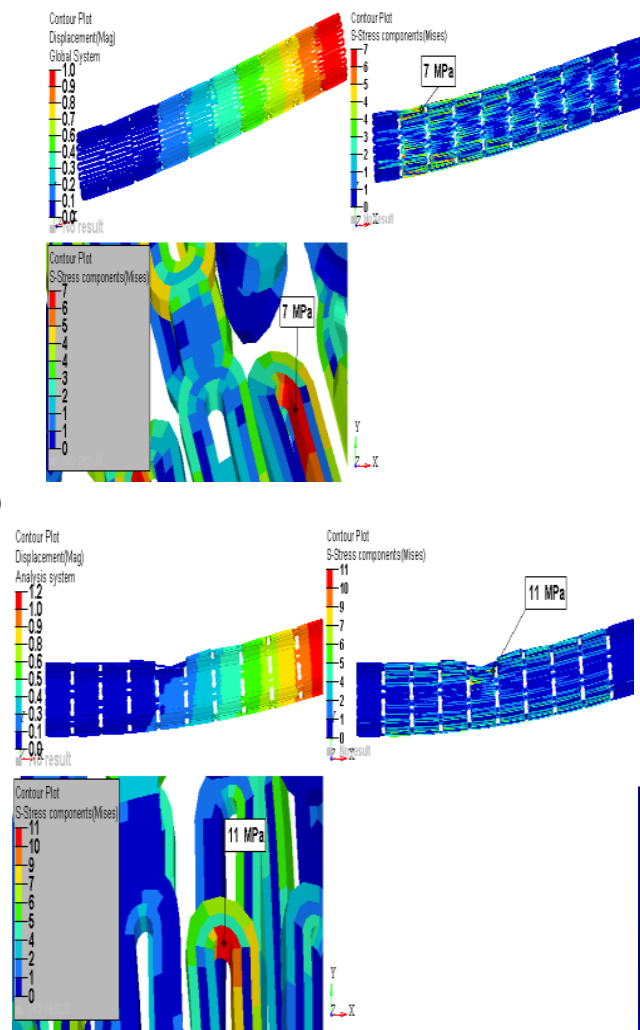

(c)

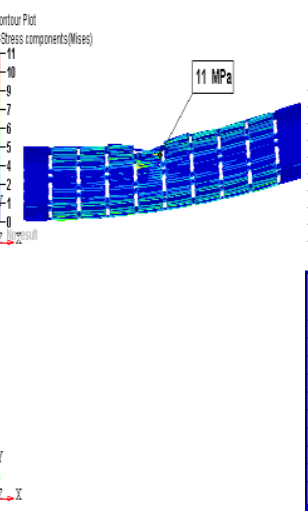

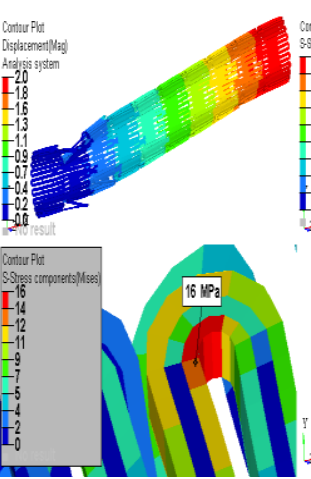

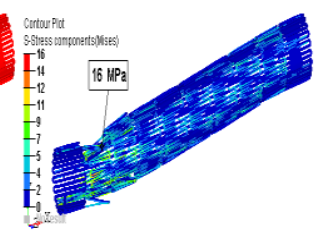

(b)

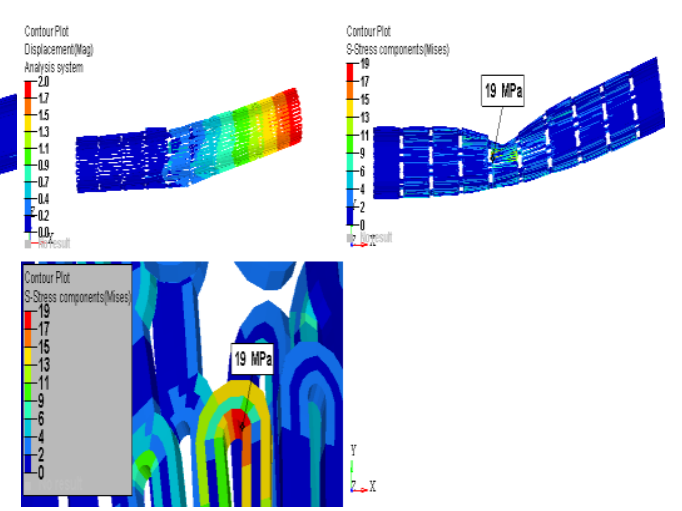

(d)

Fig.3 Displacement and von-mises stress distribution of PEEK 450G stent when subjected to (a) $1 \mathrm{~mm}$ displacement (b) $2 \mathrm{~mm}$ displacement with 0.1 radian rotation(c) 0.15 radian rotations, (d) 0.25 radian rotations

\section{RESULTS AND DISCUSSION}

Table .3 Comparison of Von-Mises stresses in PEEK450G, Magnesium AZ31 and Cobalt-Chromium L605 when subjected to different loading cases i.e., $1 \mathrm{~mm}$ displacement, $2 \mathrm{~mm}$ displacement with 0.1 radian rotation, 0.15 radian rotation and 0.25 radian rotation.

\begin{tabular}{|c|c|c|c|c|c|}
\hline \multirow{2}{*}{ Sl.no } & \multirow{2}{*}{ Materials } & \multicolumn{4}{|c|}{ Von -Mises Stress (Mpa) } \\
\cline { 3 - 6 } & & Case-1 & Case-2 & Case-3 & Case-4 \\
\hline $\mathbf{1}$ & PEEK450G & 7 & 16 & 11 & 19 \\
\hline $\mathbf{2}$ & Magnesium & 78 & 841 & 547 & 1012 \\
\hline $\mathbf{3}$ & Cobalt-Chromium & 437 & 1075 & 700 & 1294 \\
\hline
\end{tabular}

The results obtained for each stent in terms of Von-Mises stress are shown in the table.3. It is observed that the stress developed in case of PEEK450G when subjected to different loading cases i.e., $1 \mathrm{~mm}$ displacement, $2 \mathrm{~mm}$ displacement 
with 0.1 radian rotation, 0.15 radian rotation and 0.25 radian rotation are $7 \mathrm{Mpa}, 16 \mathrm{MPa}, 11 \mathrm{MPa}$, and $19 \mathrm{MPa}$ is very lesser as compare to Magnesium, and Cobalt-Chromium. And also well below the yield function of the material (100 $\mathrm{MPa})^{[28]}$, hence PEEK450G has to be a better material in terms of flexibility and stability than Magnesium and CobaltChromium.

\section{CONCLUSION}

The paper presents a non linear bending analysis of coronary stents used in the treatment of blood vessel stenosis. According to the analysis, von-mises stresses obtained for the different stent materials PEEK 450G, Magnesium AZ31 and Cobalt-Chromium are $7 \mathrm{MPa}, 78 \mathrm{MPa}$ and $437 \mathrm{MPa}$ at first load case. The stresses obtained for PEEK $450 \mathrm{G}$ is very lesser than other two materials, and also well below the yield function of the material 100MPa, hence PEEK $450 \mathrm{G}$ has to be a better material in terms of flexibility and stability than Magnesium AZ31 and Cobalt-Chromium L605.

\section{REFERENCES}

[1] David Chua SN, Mac Donald BJ, and Hashmi MSJ, Finite element simulation of stent and balloon interaction, journal of materials processing technology 2003, pp 143-144.

[2] Cardiovascular disease statistics, American Heart Association. 1988: ICD/9, pp 390-459.

[3] Pericevic I, Lally C, Tonner D, and Kelly DJ. The influence of plaque composition on underlying arterial wall stress during stent expansion, 2009, pp 428-433.

[4] S.Garg and P.W.Serruys, Coronary stents: Current status, vol 56, 2010, pp S1-S42.

[5] S.Yusuf, D.Zucker, E.Passamani, T.Takaro, and L.D Fisher, Effect of coronary artery bypass graft surgery on survival, vol 344, 1994, pp 563570

[6] Lim D,Cho SK,Park WP, Kristensson A, and Al-Hassani STS, Suggestion of potential stent design parameters to reduce restenosis risk driven by foreshortening or dog bonning due to non uniform balloon stent expansion, 2008, pp 1118-1129.

[7] Li N, Zhang H, and Ouyang H, Shape optimization of coronary artery stent based on a parametric model. J finite element in analysis and design, 2009, pp 468-475.

[8] Shravan S. Pargaonkar, Mangesh S. Prabhuue, A polyayletherketone biomaterial for use in medical implant applications, vol 5, 2015, pp 1-3

[9] Craig Bonsignore, Open stent design, NDC, 47533 Westinghouse Drive Fremont, CA, 94577, 2011, pp 20-47

[10] Schiavone, Tensile behavior for SS316L, Co-Cr L605 and Mg alloy, phd thesis, 2015, pp 65-67.

[11] VICTREX®,The mechanical properties of PEEK 450G medical document data is considered as per room temperature, 2014, pp 1-4 